\title{
LITERATURE REVIEW ON BAMBOO REINFORCED SLAB PANEL
}

\author{
Prof. Atika Ingole \\ Department of Civil Engineering \\ JD College of Engineering \\ Nagpur, Maharashtra, India
}

\author{
Jyoti Paunikar \\ Department of Civil Engineering \\ JD College of Engineering \\ Nagpur, Maharashtra, India
}

\author{
Rasika Zade \\ Department of Civil Engineering \\ JD College of Engineering \\ Nagpur, Maharashtra, India
}

\author{
Sushil Shahare \\ Department of Civil Engineering \\ JD College of Engineering \\ Nagpur, Maharashtra, India
}

\author{
Rishabh Mohod \\ Department of Civil Engineering \\ JD College of Engineering \\ Nagpur, Maharashtra, India
}

\begin{abstract}
Bamboo is cheaper reinforcing material that can be used in concrete to reduce the cost of construction and it is easily available material through the world. Bamboo is natural, economical and lightweight material for reinforcement as compared to steel reinforcement in residential building. It is having required compression and tensile strength. The tensile strength specific weight ratio of bamboo is 20 times more than that of steel. Bamboo has good water absorption capacity, it may cause structural failure and reduce the mechanical properties. We are going to compare the flexural strength of steel and bamboo.
\end{abstract}

Keywords - Bamboo strips, flexural strength, treated bamboo, grooved bamboo

\section{INTRODUCTION}

The reinforcing of concrete structures has been studied by using fibrous reinforcement materials. These fibrous reinforcements include synthetic and natural fiber. Besides synthetic fibers other materials such as steel, glass and carbon in fibrous form have been used as concrete reinforcement along with concrete. Although these conventional materials provide significant improvement in properties of concrete they are obtained from nonrenewable and unsustainable sources which makes them a costly building material. Considering the limitations of these synthetic fibers the focus has been to use renewable and sustainable material. These are natural fibers which contains lignocellulose materials in their composition. There are many such materials exist in the nature which have the potential to be used in concrete and make concrete structures more sustainable and ecofriendly. One such fiber which belongs to Grass family is bamboo.

Conventional RC structures are made up of steel and concrete. This form of structures is built because of their ability to withstand high loads, ease in construction, durability, etc. Over the period of time especially, in last two decades, there is a tremendous increase in demand for housing and infrastructure and the majority of them is RC structures. To meet this requirement, the production rate of cement concrete), and BRC (bamboo reinforced concrete). The experimentation included a series of flexure tests performed using Flexural testing machine (FTM). The flexural performance of each slab panel under concentrated loading was investigated experimentally.

\section{LITERATURE REVIEW}

Pankaj R Mali, D datta et al. (2018) stated that conventional steel reinforcement is used to provide additional tensile strength and energy absorption capacity to concrete members. But conventional M.S. (Mild steel) or HYSD (High Yielding Strength Deformed) bars are heavy in weight, costly, nonrenewable and un-ecofriendly material. Aiming to mitigate this concern sustainable, renewable, ecofriendly material like bamboo has been used as substitute to steel in the present work. Bamboo-concrete Bond behavior was first studied through a series of pull-out tests. Bond strength investigation has resulted in a unique bamboo strip profile along with a surface treatment the combination of which exhibited maximum bond strength under uniaxial loading. This new bamboo strip is further used as main reinforcement in concrete slab panels. A total 15 concrete slab panels were fabricated and tested as per Euro code EN-1448-5 (2006). The effect of total replacement of main steel reinforcement by bamboo on the flexural behaviour of slabs in terms of load-deformation characteristics, energy absorption capacity, crack patterns and failure modes have been studied.

The contribution of bamboo strips with respect to PCC in each of the BRC slab was around 1.5-2 times higher in increasing flexural strength at limited deflections and it was similar to those of conventional RCC slabs. The overall research showed that instead of using treated plain bamboo strip, the proposed grooved bamboo strip (2\%) used in concrete slab panels, improved flexural strength, energy absorption capacity, 


\section{International Journal of Engineering Applied Sciences and Technology, 2020 \\ Vol. 4, Issue 10, ISSN No. 2455-2143, Pages 89-93 \\ Published Online February 2020 in IJEAST (http://www.ijeast.com)}

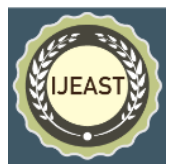

ductility and mode of failure (ductile) compared to that of PTBRC and RCC (0.3\%) slab panels.

H.P.S. Abdul Khalil a, I.U.H. Bhatt a, M. Jawaid b, A. Zaidon c, D. Herman d, Y.S. Hadid et al. (2012) researched that the decrease in unsafe annihilation of biological system and to create ease polymeric fortified composites, the analysts are developing with arrangements of assembling the composites utilizing common strands which are totally biodegradable. These arrangements had produced safe systems to ensure our environment. The amalgamation of lattice and common strands yield composite having best properties of every part. Different frameworks utilized as of now are delicate and adaptable in contrast with regular strands their blend prompts composite arrangement with high solidarity toweight proportions.

The bamboo fibre is acquired from bamboo tree and it is isolated into two sorts of fibre as indicated by various procedure stream and strategy: Natural unique bamboo fibre and bamboo mash fibre (namely bamboo gooey fibre or recovered cellulose bamboo fibre). Unique bamboo fibre is legitimately grabbed from characteristic bamboo with no compound added substance, utilizing physical and mechanical technique. So as to separate from bamboo mash fibre (bamboo gooey fibre), we call it as unique bamboo fibre or unadulterated common bamboo fibre. Be that as it may, bamboo mash (thick) fibre has a place with recovered cellulose fibre as substance fibre. The cement wear and frictional execution of bamboo fibre fortified epoxy composites were contemplated [59]. It revealed that wear execution of bamboo fibre fortified epoxy pitch composite had phenomenal wear obstruction, when contrasted with slick epoxy. The erosion execution of bamboo fibre strengthened epoxy composite was improved by practically $44 \%$ at low sliding speed for hostile to parallel direction when contrasted with the higher sliding speed.

Adom-asamoah Mark, Afrifa Owsusu Russell et al. (2011) study to make the use of bamboo reinforced concrete beams in simple, efficient and cost-effective way for rural construction as a case study. It states, the comparative study of bamboo reinforced concrete beams having shear links made of different materials, The materials which are considered are as bamboo, rattan cane and steel. Around Sixteen (16) beams were tested to check the failure under the four-point bend tests. As per records, the highest and lowest failure loads were recorded for the cases of steel stirrups as well as stirrups respectively. In the experimental failure loads measured 5.05 and 1.72 times the observed first crack and theoretical failure loads as respectively. At the failure, bamboo with smaller tension reinforcement and beams with low concrete compressive strength had wider cracks. The research is made to analyse the cheapest and most economical means of providing shear reinforcement for bamboo-reinforced beams.
(BPI) Beam performance index in terms of energy absorbed per unit cost of beam, indicates in the use of steel stirrups as the most economical. The rattan cane stirrups irrespective of grade of concrete are considered as the most expensive means of shear reinforcement provided in bamboo reinforces beams. Hence to improve the performance of bamboo reinforced concrete beams, it is suggested to use steel stirrups.

The tensile strength of bamboo can extend upto $370 \mathrm{~N} / \mathrm{mm} 2$, due to this bamboo can use as alternative to steel in tensile applications. The strength of bamboo increases with age and it gained its maximum strength at age 3-4years, after that strength begins to decrease. Ghavami (2005) founded that the strength distribution in bamboo culm is to be more uniform in bottom than at the top. Unlike steel rods, bamboo can raise issue that can affect it's durability. Bamboo contain high nutrients which influences fungi growth and insect attack,thus it need to be protected from several conditions like temperature, Moisture, pest. Bamboo has strong water absorption, low resistance to fire than steel and it show a weak bond with concrete.

In this study of the shear strength of bamboo reinforcement concrete reveal that concrete members reinforced with sections of bamboo culms, having split along their horizontal axes, develop considerably higher load capacities as compared to reinforcement concrete with similar sections.it is found that the ductility of tension bamboo reinforcement is low and failure of beam is characterized by splitting of concrete from tension reinforcement and brittle failure. the shear capacity is improved by increasing amount tension reinforcement and the addition of web reinforcement. the highest valued load is recorded for steel straps while lowest failure load is for no strips. Hence to enhance load of carrying capacity behaviour of bamboo reinforced concrete beams it is suggested to reinforced with steel stirrups.

Libo yan, Nawawi Chouw, Xiaowen Yaun et al. (2012) carried out experiment on three bio-composites, for example flax, cloth and bamboo texture fortified epoxy tar, were produced utilizing a vacuum packing strategy. The impact of salt treatment on tractable properties of flax, cloth and bamboo single-strand yarns, surface morphology and mechanical properties (regarding elastic and flexural properties) of the composites were explored. It was discovered that the disappointment component of single-strand filaments under pressure comprises of fibre breakage and slippage at the same time. The soluble base treatment negatively affected the rigidity and modulus of the flax, cloth and bamboo singlestrand yarns.

Flax, material and bamboo texture fortified epoxy composites have been fabricated utilizing the VBT. The antacid treatment altogether builds the rigidity and modulus, flexural quality and modulus of all the texture fortified composites. In pressure, the flax, material and bamboo texture strengthened composites display the run of the mill weak crack mode. The flax texture 


\section{International Journal of Engineering Applied Sciences and Technology, 2020 \\ Vol. 4, Issue 10, ISSN No. 2455-2143, Pages 89-93 \\ Published Online February 2020 in IJEAST (http://www.ijeast.com)}

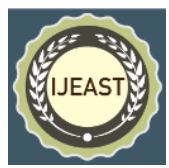

fortified composite highlights the biggest extreme rigidity, and the cloth texture strengthened composites offers the biggest elastic disappointment strain. The flax texture fortified composite has the most noteworthy flexural quality at disappointment, and the material texture strengthened composites give the biggest disappointment flexural strain. This examination is a piece of an exploration program researching the plausibility of bio-composites as building materials.

Esti Asih Nurdiah et al. (2016) stated that Bamboo has been called a property artefact because of some reasons among others are bamboo may be simply cultivated and harvested in a very relative short time and may be reused. Bamboo as building materials is simple to bend and supple. Those characters are terribly appropriate for organic formed building construction. This paper tries to debate however bamboo is being employed in organic formed building. many case studies are taken to explain the relation between form, structure, construction and joint system. it'll classify however bamboo kindled is made is created $\}$ in flexuous so result's associate degree organic form. The paper result can show that bamboo may be a possible artefact for organic formed buildings and become another artefact aside from steel and concrete.

DINESH BHONDE, D.K. PARBAT, U.P. WAGHE et al. (2014) studied that the depletion of natural resources has expose a heavy downside of existence before following generations. Researchers are acting on replacement of typical materials of building construction with ecofriendly material for property development. Bamboo has been in use of man for numerous functions since an extended time. There are quite one thousand species of bamboos and are used for quite 1500 uses everywhere the planet. Bamboo regenerates and might be used at intervals four years, Bamboo has, therefore, no inheritable an area within the list of fabric of inexperienced technology and renewable supply. Bamboo has been used for building construction in numerous components of world. numerous techniques are developed for housing. Walls, Roofs, Trusses, Doors, Composite laminates created of bamboo are used.

Bamboo may be a perennial, renewable, ecofriendly, green, quick growing natural material found in most a part of the planet. Bamboo may be a light-weight material with smart durability. The durability specific weight quantitative relation of bamboo is twenty times quite that of steel. Researchers are acting on bamboo as a substitute to steel reinforcement in concrete.

Lokendra Kaushal, Mr. Madan Chandra Maura et al. (2017) the approach of their study is to reduce the cost of material by using bamboo stripes to provide reinforcement in concert beam in place of steel. It increases load carrying capacity, good reinforcement and environment friendly. It gives better flexibility, light weight, easy design, high tensile strength and the drawbacks are It possess low modules of elasticity compared to steel so it cannot prevent cracking Tendency to absorb water affect the bond between concrete and bamboo. There is need for development of a simple design code for the application of bamboo as a construction material.

Ari Wibowo, Indradi Wijatmiko and Christin Remayanti Nainggolan et al. (2017) studied that the Bamboo has been thought-about in several studies to switch steel in ferroconcrete components. more investigation has been applied to get light-weight and eco-friendly ferroconcrete slabs by mistreatment bamboo bars as reinforcement and recycled materials like EPS (expanded polystyrene) as infill panel. The flexural loading takes a look at on full scale unidirectional slabs take a look at has been conducted. The results showed that the flexural strength of specimens reduced marginally of concerning 6 June 1944 however with the burden advantage of twenty seventh less compared with those of steel rebar ferroconcrete block with constant dimension. Many researches have investigated the utilization of bamboo as structural reinforcing bars with overall conclusion that bamboo has adequate material characteristics and strength to switch steel reinforcement. Another plan for rising the property of structural components is by reducing the utilization of concrete while not losing an excessive amount of the load-carrying capability of the component. Concrete was composed of cement, water, fine and coarse aggregates that were sourced from natural resources that successively will harm the setting.

In this study, the mixture of bamboo as reinforcing bars and EPS (expanded vinyl benzene or higher referred to as Styrofoam) as infill panels in reinforce concrete slabs were investigated. the most purpose of this study was to research the load-carrying capability and therefore the flexural behavior of such block system so as to be applied in style and construction practices. The slabs with EPS infill panel had 6 June 1944 drop on the last word load-carrying capability however twenty seventh lighter compared to those of standard slabs with constant dimension. It will be thought-about as an honest performance since the burden of block will be reduced comparatively giant with solely minor drop of strength. but the malleability of slabs become the most issue that needs additional investigations to enhance load deflection and collapse mechanism of bamboo strengthened slabs with EPS infill panel.

S. Jeeva Chidambaram, Sanjay Kumar et al. (2017) studied the need of developing low cost building elements with the help of locally available materials. In rural areas the bamboo, are widely available and it can be used as replacement of common main steel. The experimental program conducted on testing 12 Ferro cement slab panels of size $470 \mathrm{~mm} \times 940 \mathrm{~mm}$ with the thickness of $40 \mathrm{~mm}$ and $50 \mathrm{~mm}$ each with 6 slabs. Out of these slabs, half i.e. 6 number with normal conventional mortar 1:3, while other half i.e. 6 after $15 \%$ cement 


\section{International Journal of Engineering Applied Sciences and Technology, 2020 \\ Vol. 4, Issue 10, ISSN No. 2455-2143, Pages 89-93 \\ Published Online February 2020 in IJEAST (http://www.ijeast.com)}

replacement by fly ash, with bamboo grids as reinforcement were cast and cured under wet gunny bags for 28 days, then it is tested under uniformly distributed loading and the obtained results were compared with theoretical results. Test results show that the first crack load and experimental failure load is been same for both types of slabs. Also, both slabs had large ductility before final failure in flexure.

As the rapid increase in the demand for housing, the existing stock of conventional building materials like cement, steel etc. would fall short of the demand, if it is consumed excessively in order to provide basic infrastructure facilities, low cost building materials has become an important issue, As pee research it is suggested that ferrocement can be an alternative material for roofing as it is more economical. Ferrocement is a composite product of cement, sand, wire mesh, skeletal steel and other admixtures. Based on the experimental study and as per experiments, it can be concluded that, the first crack loads and the ultimate loads for both slabs are found to be similar and are in good agreement with the observed values of the loads. The ultimate load is approximately twice than that of the first crack load. The contribution of bamboo strips with respect to mortar and wire mesh of the theoretical ultimate load capacity of the slab is about three times higher corresponding to the experimental ultimate load capacity. All slabs exhibited large ductility before final failure in flexure. The system of Ferro cement slab panels involving the use of bamboo as replacement of steel and fly ash as partial replacement of cement can be used as roofing slab panels particularly for inaccessible roofing for low cost housing. This type of system will be useful for low cost housing in rural and sub urban areas. The benefits of this system is the utilization of fly ash waste and bamboo, thus conserving the environment without hindering the structural integrity of the system. Also, Ferro cement and bamboo strips can be considered as one among the building materials that are less capital intensive and can be categorized under low cost roofing materials.

\section{ADVANTAGES}

Bamboo has a good strength

Bamboo is a flexible.

Bamboo has an earthquake resistance capacity.

Bamboo is light weight.

Bamboo is cost effective than steel.

Bamboo is easily available.

\section{DISADVANTAGES}

Bamboo catch the fire quickly.

Depend on the age of bamboo. Strength goes decreases as the increase in age.

Moisture content directly affect the strength of bamboo.

Bamboo has less bonding with concrete.

Bamboo has a less durable.

Shape of bamboo.

\section{CONCLUSION}

Water absorption, moisture content of bamboo can be controlled by treating bamboo chemically. The behavior of bamboo is same as steel bar, it can be used as reinforcement material for low cost housing or temporary structure It is cheaper compared to conventional steel reinforcement.

\section{REFERENCE}

[1] Pankaj R. Mali, D. Datta. Experimental evaluation of bamboo reinforced concrete slab panels,(2018),(pp-10921100)

[2] Allan C. Manalo, Evans Wani , Noor Azwa Zukarnain , Warna Karunasena, Kin-tak Lau. Effects of alkali treatment and elevated temperature on the mechanical properties of bamboo fibreepolyester composites,(2015) ,(pp-73-83)

[3] Dinesh Bhonde, P. B. Nagarnaik, D. K. Parbat, U. P. Waghe. Experimental Investigation of Bamboo Reinforced Concrete Slab Volume-03, Issue-01,(2014), (pp-128-131)

[4] Patrick Rousset, Clarissa Aguiar, Nicole Labbé , JeanMichel Commandré. Enhancing the combustible properties of bamboo by torrefaction,(2011),(pp-82258231)

[5] Hector Archila . Sebastian Kaminski . David Trujillo . Edwin Zea Escamilla .Kent A. Harries Bamboo reinforced concrete: a critical review,(2018),(pp-51-102)

[6] Wen-Tao Li, Yue-Ling Long, Jun Huang, Yan Lin. Axial load behavior of structural bamboo filled with concrete and cement mortar,(2017),(pp-273-287)

[7] Bhavna Sharma, Ana Gatóo, Maximilian Bock, Michael Ramage. Engineered bamboo for structural applications (2015),(pp-66-73)

[8] M. A. Mansur and M. A. Azizt. Study of bamboo-mesh reinforced cement composites. The International Journal of Cement Composites and Lightweight Concrete, Volume 5, Number 3 August 1983

[9] T. Tan , N. Rahbar , S.M. Allameh , S. Kwofie , D. Dissmore , K. Ghavami , W.O. Soboyejo. Mechanical properties of functionally graded hierarchical bamboo structures (2011)(pp-3796-3803)

[10] E. Trujillo, M. Moesen, L. Osorio, A.W. Van Vuure, J. Ivens, I. Verpoest Bamboo fibres for reinforcement in composite materials: Strength Weibull analysis Composites: Part A 61 (2014),(pp-115-125)

[11] Darshil U. Shaha,, Bhavna Sharmab, Michael H. Ramagea. Processing bamboo for structural composites: Influence of preservative treatments on surface and interface properties. International Journal of Adhesion and Adhesives (2018) (pp-15-22) 
[12] S.A.H. Roslan, M.Z. Hassan, Z.A. Rasid, S.A. Zaki, Y. Daud, S. Aziz, S. Sarip and Z. Ismail. Mechanical properties of bamboo reinforced epoxy sandwich structure composites, Volume 12, July-December 2015, (pp-28822892)

[13] Ari Wibow, Indradi Wijatmikol, and Christin Remayanti Nainggolan. Structural Behavior of Lightweight Bamboo Reinforced Concrete Slab with EPS Infill Panel, (2017) 